\title{
California's
}
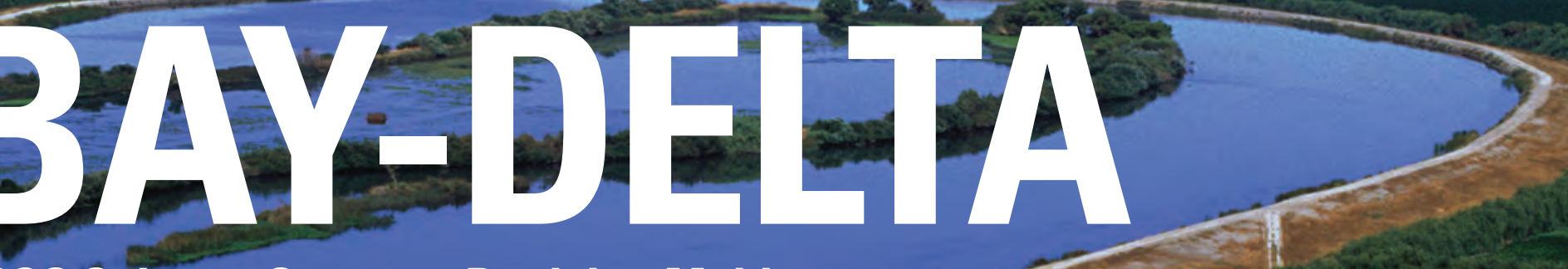

USAS Science Supports Decision Making

U.S. Geological Survey (USGS) scientists are in the forefront of the effort to understand what causes changes in the hydrology, the ecology and the water quality of the Sacramento-San Joaquin River Delta and the San Francisco Bay estuary. Their scientific findings play a crucial role in how agencies manage the Bay-Delta on a daily basis.

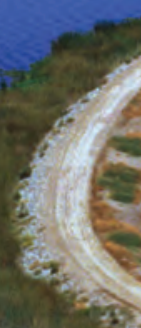

\section{About the Delta}

in the Delta for decades. Recent work includes:

- Developing a network of real-time flow monitoring stations. The stations have recently been augmented to measure turbidity, or water cloudiness - information that may help agencies avoid conflicts between water exports and threatened fish.

- Determining the causes and rates of decreased sediment supply and turbidity in the Delta, which may have implications for Delta smelt survival.

- Tagging and tracking thousands of juvenile salmon as they move into Delta channels to better understand how flow conditions, channel geometry and fish behavior affect salmon survival.

- Developing the first experimental wetland to capture atmospheric carbon-a greenhouse gas — while rebuilding land surfaces on a sunken Delta island.

- Studying the Delta's complex water-quality issues, including mercury, pesticides and dissolved organic carbon.
Together, the Sacramento-San Joaquin River Delta and San Francisco Bay comprise the largest estuary on the West Coast. The Delta is:

- The hub of California's water-delivery system.

- A source of water for more than 20 million Californians and for millions of acres of farmland in the San Joaquin Valley.

- Habitat for hundreds of species of wildlife, including the threatened Delta smelt, which spends its entire one-year lifespan in the estuary. Winter-, fall- and spring-run salmon migrate through the Delta on their way to spawn in Central Valley rivers. 


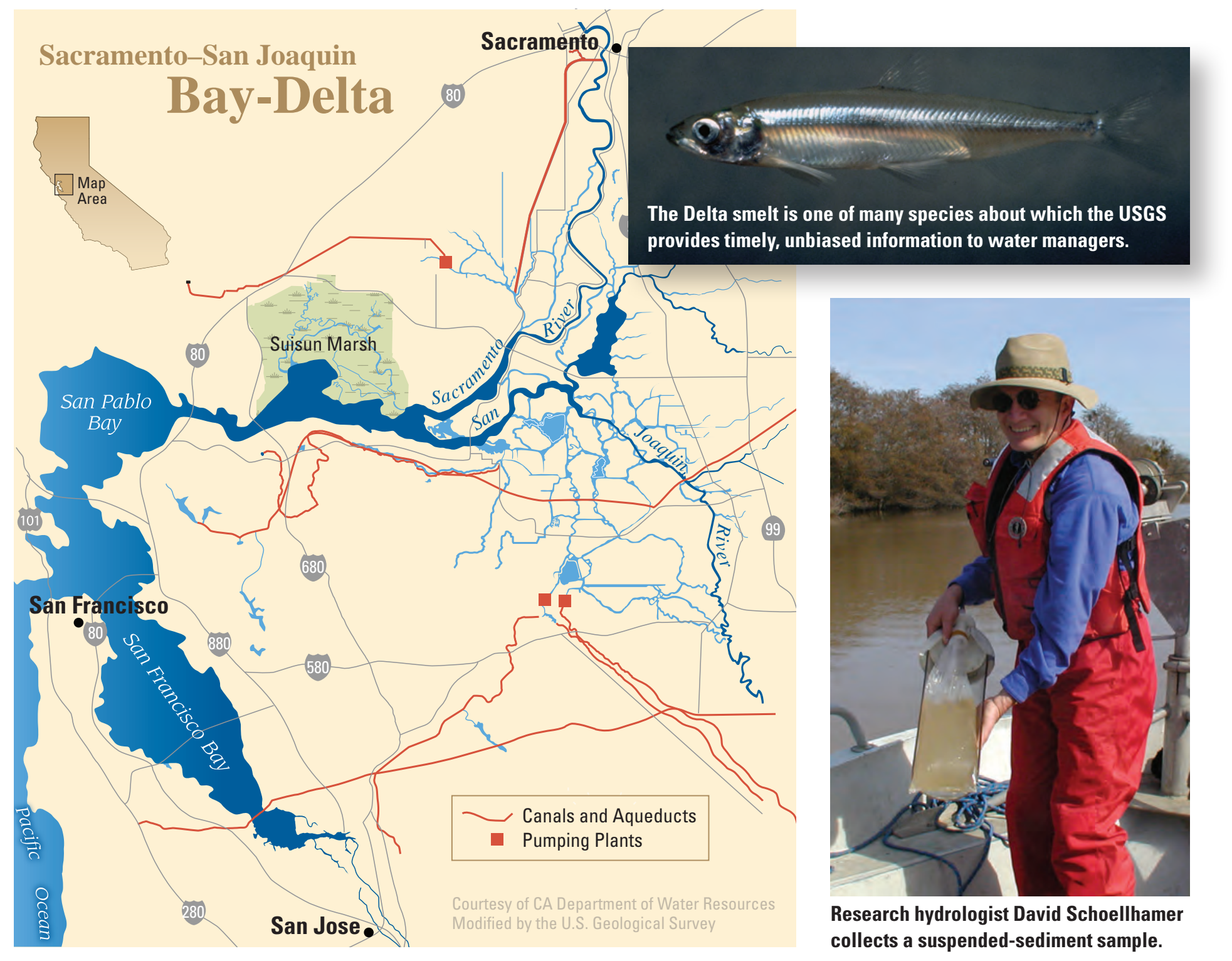

\section{USGS Research Tackles Criticall Bay-Deltal Issues}

\section{Below is a summary of some of the issues facing} the Delta, and the role that USGS science has played in devising innovative new strategies and solutions.

\section{Hydrodynamics and Fish-Related Research}

Researchers with the USGS California Water Science Center have a long track record of providing Federal and State resource managers with timely and unbiased information about fish species in the Sacramento-San Joaquin Delta. This work has helped lead to the current state of knowledge about the Delta smelt - which is at the heart of many of the State's water conflicts - other fish, and the food web. USGS research includes:

- The development and operation of a network of real-time data collection sites that monitor the flow of water in and out of the Delta. Using this data, scientists found a strong correlation between the direction and magnitude of water flowing in central Delta channels and the number of Delta smelt affected by water exports.

- Field studies in two flooded Delta islands - Franks Tract and Mildred Island - which showed a direct link between Delta flow patterns and the amount and kind of food available to organisms living on the bottom of the estuary. This is important knowledge for understanding the food web in the Delta.

- Studies of sediment flowing into the Delta and how it relates to channel turbidity. A preliminary sediment survey was conducted in February 2010. Initial findings are encouraging and support the hypothesis that Delta smelt seek turbid - or cloudy - water and avoid clearer water. A full study is planned for the winter of 2010-2011. These results may lead to new strategies to help water agencies avoid adverse effects to smelt.

\section{Juvenile Salmon Survival}

To better understand how Delta hydrology affects the migration of juvenile salmon, USGS scientists conducted a salmon-tracking study that used the USGS flow-station network and new acoustic salmon-tracking technology. The study mapped exactly how juvenile salmon move through Delta 


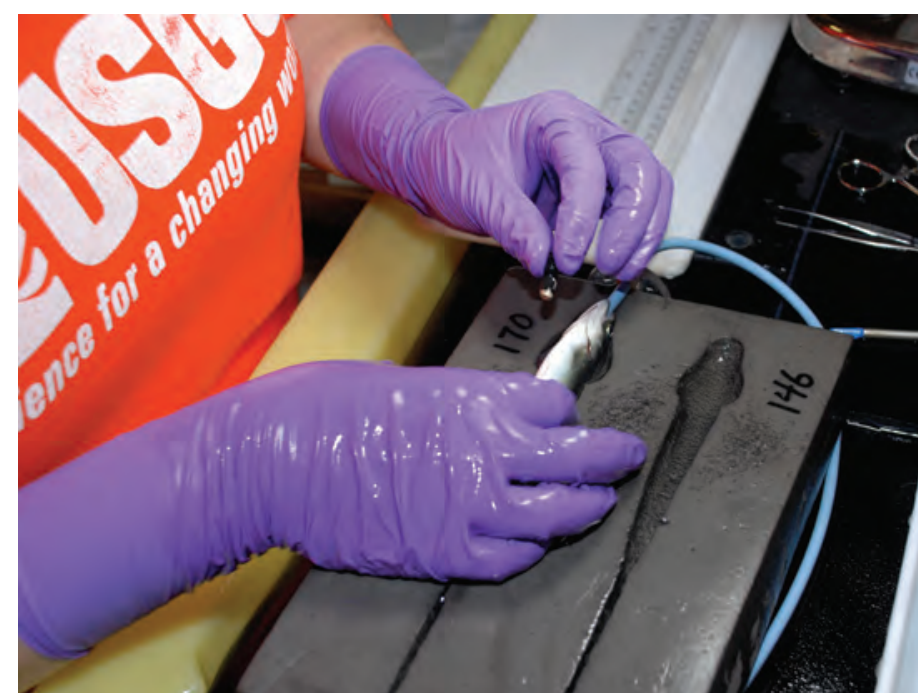

A juvenile salmon is tagged with an electronic sensor and that allows scientists to track its migration.

channels, where they can and cannot survive, and how water operations and river flows affect these patterns.

The USGS salmon-migration tracking study was designed to give water and fishery managers the capability to predictfor the first time - how specific water operational and river-flow conditions affect fish movement. By analyzing these data, scientists hope to glean findings that could have a real and positive effect on current and future Delta operations. These findings could be particularly useful during critical water years when salmon populations are low.

\section{Delta "Carbon Farm"}

Imagine a new kind of farming in the Sacramento-San Joaquin River Delta - "carbon-capture" farming, which traps atmospheric carbon dioxide and rebuilds lost soils. The USGS California Water Science Center, in partnership with California Department of Water Resources (DWR) and the University of California, Davis, is making it happen.

Long-standing farming practices in the Delta expose fragile peat soils to wind, rain and cultivation, emit carbon dioxide $\left(\mathrm{CO}_{2}\right)$ and cause land subsidence, or a decline in land-surface elevation. To capture or contain the carbon, farmers would "grow" wetlands. In doing so, they would begin to rebuild the Delta's unique peat soils, take $\mathrm{CO}_{2}$ out of the atmosphere, ease pressure on the Delta's aging levees and infuse the region with new economic potential.

Carbon-capture farming works as $\mathrm{CO}_{2}$ is taken out of the air by plants such as tules and cattails. As the plants die and decompose, they create new peat soil, building the land surface over time.

The USGS and DWR partnered on a pilot project that shows the promise of carbon-capture farming. On deeply subsided Twitchell Island in the western Delta, USGS scientists recorded elevation gains of more than 17 inches from 1997 to 2005 on two seven-acre test plots as cattails, tules and other plants grew, died and decomposed. The process leaves behind roots and plant remnants that compact into a material similar to what formed the peat soils initially.

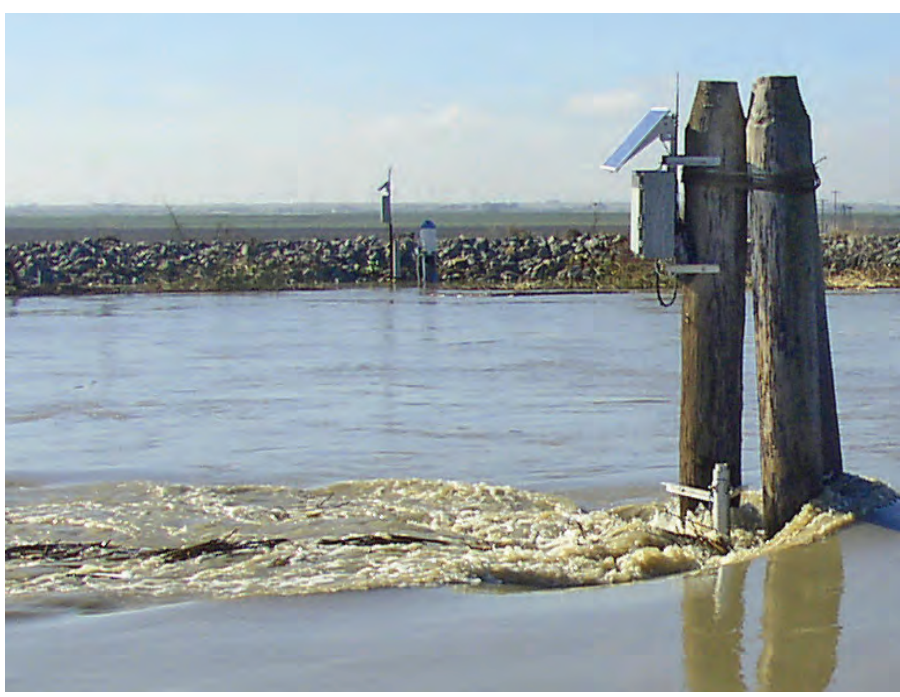

Flow-station instruments mounted on a piling measure direction and amount of water flowing in a Delta channel.

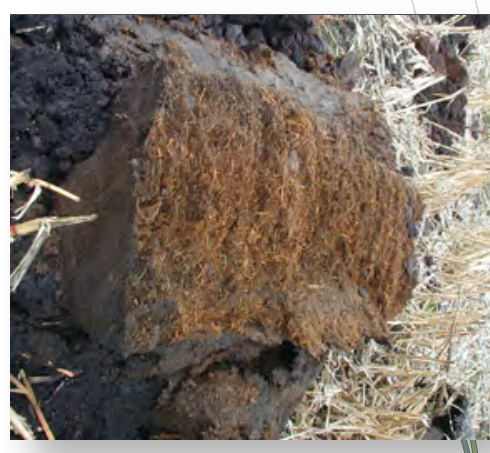

Unique peat soils capture atmospheric carbon, a greenhouse gas.

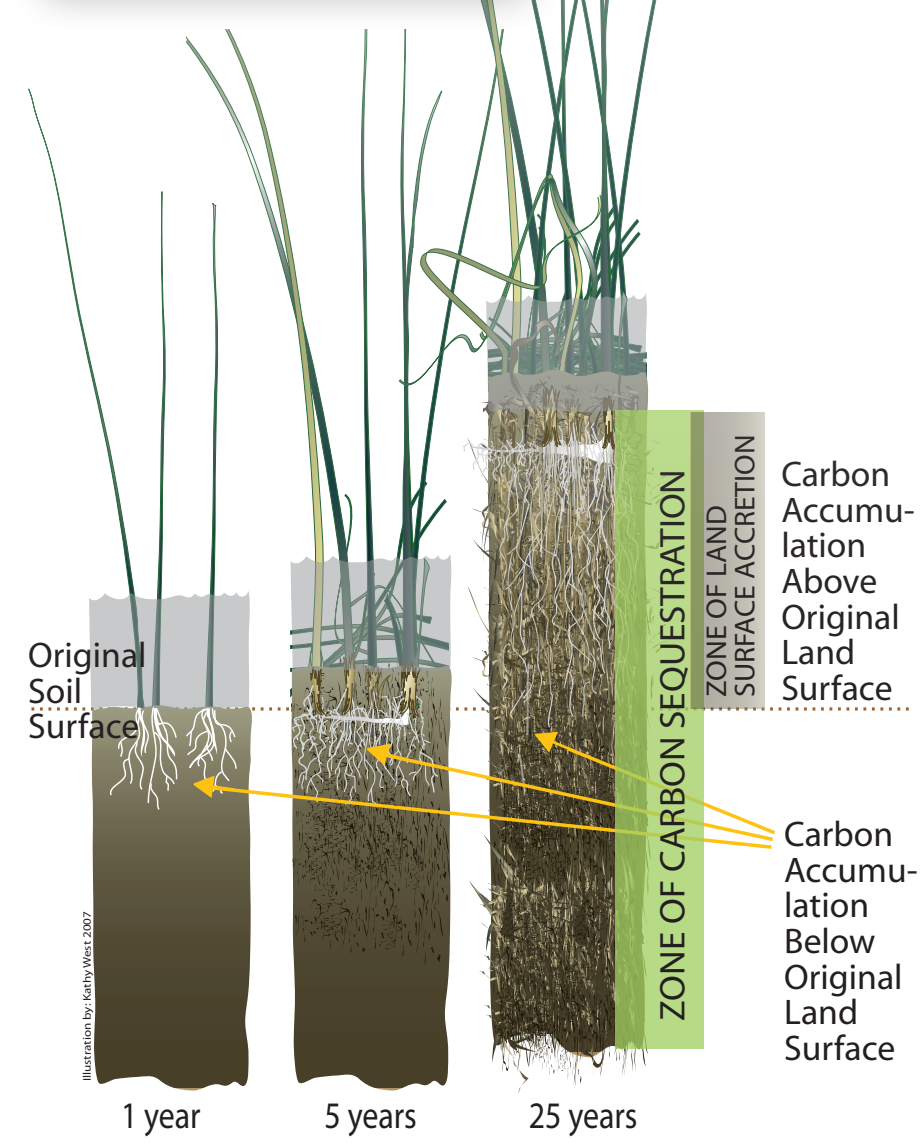

Growing new peat bolsters a subsided Delta island. 


\section{Studies of Pesticides and Their Effects in the Delta}

A wide variety of pesticides-more than 200 different compounds-currently are in use in California. For more than a decade, the California Water Science Center has conducted studies to determine the occurrence and fate of a number of these pesticides in surface waters throughout the State.

One potentially troubling change in pesticide application is the increased use of pyrethroid insecticides, which are highly toxic to aquatic invertebrates and fish, especially cold-water fish such as salmon. The USGS has developed methods to analyze pyrethroids at low levels in water, sediments, and biota and is conducting studies to determine their occurrence, transport, and fate in the hydrologic cycle.

Reconnaissance work has demonstrated the presence of pesticides in Delta waters in concentrations that have been linked to toxicological effects in juvenile salmon. These pesticide studies are part of larger USGS efforts to understand the causes of the decline of pelagic (open-water) organisms in San Francisco Bay and to predict the effects of increasing urbanization on aquatic ecosystems.

\section{Delta Wetland Restoration and Potential Mercury Impacts}

The California Gold Rush left 10 million tons of mercury in the Central Valley watershed. Streams and rivers have transported this mercury as far as the Delta and even San Francisco Bay. But the bacterial transformation of mercury into the form that moves into the food-chain (methyl mercury) has only occurred at a limited rate in some places. Wetlands are known to be optimal environments for this transformation, and there is concern that wetland restoration in the Delta may cause increases in food-web mercury. A number of USGS studies are focused on determining if this is a risk, and if so, what management practices may mitigate it.
Scientists from the USGS California Water Science Center have pioneered the use of new water-quality monitoring sensors to measure mercury flowing on to and off of tidal wetlands. These sensors are akin to mini-laboratories and are placed in the water where they analyze samples as frequently as every 15 minutes for up to several days at a time. These high frequency measurements are critical in tidal environments where water flows in two directions and speed changes frequently. Preliminary results show that tidal wetlands can be net sources of methyl mercury.

\section{Future Directions in Bay-Della Studies}

The critical issues facing California's water supply, and particularly the issues involving the central water hub of the Sacramento-San Joaquin Delta and San Francisco Bay, pose continuing and evolving challenges to scientists and water managers. The USGS California Water Science Center has proposed new studies to help us understand how the Delta works as an estuary and an ecosystem. These proposed efforts should provide policy-makers and agencies with modeling tools to test various water-management and ecosystem-restoration scenarios. The current and future studies in the Bay-Delta are part of the USGS efforts to understand our vital water resources and guide sound management of those resources.

For more information on USGS research in the Bay-Delta and the California Water Science Center, visit our Web site at http://ca.water.usgs.gov/ or call our Sacramento Project Office at (916) 278-3000 or the San Diego Project Office at (619) 225-6100.

Contacts at the California Water Science Center: Eric Reichard, Director (egreich@usgs.gov)

Donna Schiffer, Deputy Director (schiffer@usgs.gov) Roger Fujii, Bay-Delta Projects Chief (rfujii@usgs.gov) Kim A. Taylor, Program Officer (ktaylor@usgs.gov) James Nickles, Public Affairs Specialist (jnickles@usgs.gov) 